\title{
Nuclear receptors and chromatin: an inducible couple
}

\author{
Raffaella Maria Gadaleta and Luca Magnani \\ Division of Cancer, Imperial Centre for Translational and Experimental Medicine, Imperial College London, \\ London, W12 0NN, UK
}

Correspondence should be addressed to L Magnani Email

I.magnani@imperial.ac.uk

\begin{abstract}
The nuclear receptor (NR) family comprises 48 transcription factors (TFs) with essential and diverse roles in development, metabolism and disease. Differently from other TFs, NRs engage with well-defined DNA-regulatory elements, mostly after ligand-induced structural changes. However, NR binding is not stochastic, and only a fraction of the cognate regulatory elements within the genome actively engage with NRs. In this review, we summarize recent advances in the understanding of the interactions between NRs and DNA. We discuss how chromatin accessibility and epigenetic modifications contribute to the recruitment and transactivation of NRs. Lastly, we present novel evidence of the interplay between non-coding RNA and NRs in the mediation of the assembly of the transcriptional machinery.
\end{abstract}

\section{Introduction/overview}

Nuclear receptors (NRs) are evolutionarily related DNAbinding transcription factors (TFs) (Gronemeyer et al. 2004, Chambon 2005, Evans 2005). They regulate many aspects of mammalian physiology, including metabolism, development and reproduction (Mangelsdorf et al. 1995, Willy et al. 1995, Chawla et al. 2001), priming the activation of multiple genes to achieve accurate, synchronized and coherent functional responses. Most NRs regulate gene transcription in response to a ligand activation process, being activated by several hormones, vitamins, lipophilic metabolites and dietary lipids. NRs are also able to recruit a variety of classical TFs, co-regulators and proteins of the basal transcriptional machinery to target gene promoters and coordinate the whole process of gene transcription. The NR superfamily has a high potential for drug targeting, because the lipophilic ligands of NRs can easily pass through biological membranes. Consequently, NRs are the object of intensive translational research, which has resulted in their

\author{
Key Words \\ - nuclear receptors \\ - chromatin \\ - epigenetics \\ - oestrogen receptors \\ - gene expression
}

Journal of Molecular

Endocrinology

(2014) 52, R137-R149 establishment as drug targets for several pathological conditions. Currently, 13\% of all FDA-approved drugs target NRs (Overington et al. 2006). These include thiazolidinediones targeting the peroxisome proliferatoractivated receptor (PPAR) in type II diabetes patients, steroids targeting the glucocorticoid receptor (GR) in inflammatory diseases, tamoxifen targeting the oestrogen receptor- $\alpha(E R \alpha)$ in breast cancer and antiandrogens targeting the androgen receptor (AR) in prostate cancer.

In 1985, the GR was the first NR to be cloned (Hollenberg et al. 1985), followed by the ER and thyroid hormone receptor (THR; Walter et al. 1985, Greene et al. 1986, Sap et al. 1986). To date, the NR superfamily comprises 48 members in humans. NRs mediate gene transcription via distinct mechanisms, including both classical genomic transactivation and transrepression activities. Furthermore, NRs can also modulate different pathways in a non-genomic fashion, and their activities can be influenced by post-translational modifications

Published by Bioscientifica Ltd 
(e.g. acetylation, phosphorylation, sumoylation and ubiquitination), making them targets of other cellular pathways. In this review, we mostly focus on the genomic activities of NRs.

Despite their broad range of activities, NRs share a common structural organization. They consist of an $\mathrm{N}$-terminal regulatory domain, containing the ligandindependent activation function 1 (AF1; Wärnmark et al. 2003) that usually has a very weak transcriptional activity (with the notable exception of the AR), but is capable of synergizing with another activation domain, activation function 2 (AF2), present in the ligand-binding domain (LBD; see below). The most conserved domain is the DNAbinding domain (DBD), which contains the P-box, responsible for direct DNA interaction and DNA-binding specificity. It consists of two zinc fingers, which recognize specific NR-responsive elements (NRREs) in the DNAregulatory regions of their target genes. NRs can bind to NRREs located in the proximity of target gene promoters and to more distal elements such as enhancer regions, as monomers, homodimers (e.g. GR, ER and AR) or heterodimers with the retinoid $X$ receptor (RXR) (e.g. farnesoid $\mathrm{X}$ receptor (FXR), liver $\mathrm{X}$ receptor (LXR) and others). NRREs consist of two hexameric core half-site motifs, separated by a variable number of nucleotides. The bipartite elements can form direct, inverted or everted repeats (Mangelsdorf \& Evans 1995). The DBD also contains a dimerization interface (Zechel et al. 1994, Germain et al. 2006, Bain et al. 2007), which can also be the site of post-translational modifications, resulting in different effects for different NRs. In some NRs, DBD phosphorylation results in decreased DNA binding (e.g. THR, Tzagarakis-Foster \& Privalsky (1998) and ER, Chen et al. (1999)); in others, it increases DNA binding and co-activator recruitment (e.g. FXR, Gineste et al. 2008). The DBD and the C-terminal LBD are connected by a flexible domain called hinge region, which houses a nuclear localization sequence (Giguère et al. 1986). The LBD presents with a structure forming a hydrophobic pocket for ligand recognition and lodging. It also contains the AF2 domain, the action of which is dependent on the presence of bound ligand (Wärnmark et al. 2003), as well as motifs responsible for dimerization and co-regulator-binding regions.

For the majority of NRs, ligand binding is the critical event shifting their function from an inactive to an active state by inducing a conformational change in the LBD (Bourguet et al. 2000). The active conformation allows the second step of NR activation: recruitment of co-regulatory complexes. In recent years, it has become clear that many of these co-factors function as chromatin-remodelling factors and can catalyse histone modifications (Kouzarides 2007, Suganuma \& Workman 2008). Small modifications of ligand structure seem to affect the co-activator-binding interface, providing a molecular basis for NR-ligand binding specificity and potency (Wu et al. 2003). The LBD is also a target for post-translational modifications, which govern a variety of cellular functions, including NR activity, DNA-binding affinity, ligand sensitivity, receptor stability and subcellular distribution. Therefore, NR post-translational modifications can ultimately result in either increased or decreased target gene expression (Balasubramaniyan et al. 2012) or in transrepression of other pathways (such as sumoylation of PPAR $\gamma$ (Pascual et al. 2005) and FXR, leading to NF- $\mathrm{KB}$ transrepression (Vavassori et al. 2009)).

\section{NR classification}

NRs can be classified in several ways. Based on ligandbinding properties, they can be divided into three classes: hormone NRs, metabolic NRs and orphan NRs (Table 1). Hormone NRs are often located in the cytosol. Once bound to their ligands, they translocate to the nucleus, usually as homodimers, and bind to their cognate NRREs. The members of this subfamily include the AR, GR and progesterone receptor (PR) and ligands include hormonal lipids. Upon ligand binding, some hormone NRs bind to the DNA on accessible chromatin at regulatory sites in the

Table 1 Classification of some members of the nuclear receptor superfamily. NRs can be classified in several ways. Based on ligand-binding property, they can be divided into hormone, metabolic and orphan NRs. Hormone NRs generally bind to the DNA as homodimers. On the contrary, most of the metabolic NRs bind to DNA as heterodimers with their obligate partner RXR. Orphan NRs can work as either heterodimers or monomers. For a more complete classification, see Nuclear Receptors Nomenclature Committee (1999)

\begin{tabular}{|c|c|c|}
\hline $\begin{array}{l}\text { Hormone } \\
\text { NRs ligands: } \\
\text { hormones }\end{array}$ & $\begin{array}{l}\text { Metabolic } \\
\text { NRs ligands: } \\
\text { dietary lipids }\end{array}$ & $\begin{array}{l}\text { Orphan } \\
\text { NRs ligands: } \\
\text { unknown }\end{array}$ \\
\hline$E R \alpha, \beta$ & $\mathrm{RXR} \alpha, \beta, \gamma$ & COUP-TFI,II,III \\
\hline GR & $\operatorname{PPAR} \alpha, \beta, \gamma$ & NUR77, NURR1, NOR1 \\
\hline MR & $\mathrm{LXR} \alpha, \beta$ & GCNF \\
\hline AR & $\mathrm{FXR} \alpha, \beta$ & LRH1 \\
\hline PR & $\mathrm{PXR} / \mathrm{SXR}$ & $\operatorname{Rev}-\mathrm{ERB} \alpha, \beta$ \\
\hline $\operatorname{RAR} \alpha, \beta, \gamma$ & CAR & SHP \\
\hline $\mathrm{THR} \alpha, \beta$ & & THR2,3,4 \\
\hline VDR & & $\mathrm{HNF} 4 \alpha, \beta, \gamma$ \\
\hline ECR & & DAX1 \\
\hline
\end{tabular}

Published by Bioscientifica Ltd 
target genes, such as ER and GR; others bind to chromatin and attract co-activator factors that have chromatinremodelling properties, as in the case of ER and PR (Vicent et al. 2011). DNA binding and chromatin remodelling then enhance the recruitment and/or function of the general transcription machinery (Fondell et al. 1996, Lefterova et al. 2008).

Metabolic receptors are typically located in the nucleus, bound to the DNA mostly as heterodimers with the RXR. In the absence of ligands, they are often complexed on the chromatin with co-repressor proteins. In this instance, ligand binding to NRs causes the dissociation of co-repressor and recruitment of co-activator proteins. Additional proteins of the basal transcriptional machinery, including RNA polymerase II, are then recruited to the NR-DNA complex to start the transcription process. The members of this subfamily include the FXR, LXR, PPARs and others, while ligands for this subgroup encompass dietary lipids. The third subgroup of NRs is the so-called family of orphan receptors, for which regulatory ligands are still unknown or may not exist (true orphans) or for which candidates have only recently been identified (adopted orphans). Members include the chicken ovalbumin upstream transcription factors (COUP-TFs), reverse ERBA- $\alpha /-\beta$, liver receptor homologue-1 (LRH1) and others.

In this review, we summarize current knowledge regarding the bidirectional crosstalk between NRs and the chromatin landscape in the context of gene regulation.

\section{Genomic features of NR binding}

Similarly to most TFs, NRs modulate transcription by binding to well-defined DNA sequences (NRREs) interspersed in the genome (Kininis \& Kraus 2008). NRs can also bind to DNA via tethering mechanisms; for example, ER $\alpha$ can 'piggyback' on AP1, MAF and RUNX1 TFs (Stender et al. 2010, Heldring et al. 2011). However, for the sake of clarity, we focus only on direct binding events. NRREs are extremely well conserved and share a significant homology. Concordantly, NR DBDs share extensive homologies (Kininis \& Kraus 2008, Willis \& Griffin 2011). Despite this, a recent NR binding survey has identified dramatically distinct topological differences in regulatory element selection (Kittler et al. 2013). Kittler et al. (2013) used a tag-based ChIP-seq approach to circumvent the noise created by different antibody efficiencies and characterized the binding profile of 24 NRs. Several NRs appear to have a strong preference for distal binding (ER $\alpha, \mathrm{RORC}, \mathrm{AR}$ and $\mathrm{PR})$. Others are found in proximity to promoter elements (testicular receptors TR2L, TR2S, TR4, LXR $\alpha$ and THR $\alpha$ (Kittler et al. 2013). Interestingly, only $32 \%$ of over $2 \times 10^{5}$ individual genomic loci have been found to recruit a single NR, suggesting that NRs exhibit extensive cooperative binding (Voss et al. 2011). For example, ten of the 24 NRs assayed are recruited to the CCND1 promoter. These genomic regions with multiple NR-binding sites (HOT regions) exhibit a significant increase in features normally associated with active regulatory elements, including epigenetic modifications and increased chromatin accessibility (Kittler et al. 2013). HOT regions are reminiscent of super-enhancers described, for example, in embryonic stem cells (Whyte et al. 2013). In this case, several regions termed super-enhancers span significantly large stretches of DNA (median size $8 \mathrm{~kb}$ ) and recruit large arrays of TFs (e.g. OCT4, SOX2, NANOG, KLF4 and ESRRB). Not surprisingly, breast cancer-relevant genes are enriched with HOT regions (e.g. CCND1 and MYC genes; Kittler et al. 2013). These data suggest that combinatorial binding patterns may play an unexpected role in hormone-dependent cancer and other physiological processes regulated by NRs.

\section{Chromatin accessibility predisposes regulatory elements to NR binding}

NRs invariably bind to regulatory elements to control cell type-specific transcription in response to external stimuli. The search for putative regulatory elements, such as promoters and enhancers, has been simplified by the recent development of epigenomics (ENCODE Project Consortium et al. 2007, 2012). Cell type-specific regulatory elements can be classified using several epigenetic modifications, including chromatin accessibility (Ernst et al. 2011). With its nucleosome-rich structure, chromatin represents the first barrier for TF binding. In agreement with this, regulatory elements are commonly found in nucleosome-depleted pockets, a conformation thought to be essential for DNA motif recognition and binding (Thurman et al. 2012). Uniquely among other TFs, several NRs bind to DNA only after conformational changes induced by their ligands (Kininis \& Kraus 2008). This raises the fundamental question about pre-induction and post-induction chromatin determinants of NR binding (Magnani \& Lupien 2013) (Fig. 1).

\section{Chromatin accessibility pre-induction}

Most of our understanding of NR-chromatin interaction comes from dissecting ER $\alpha$, GR and AR signalling. Initial

Published by Bioscientifica Ltd 

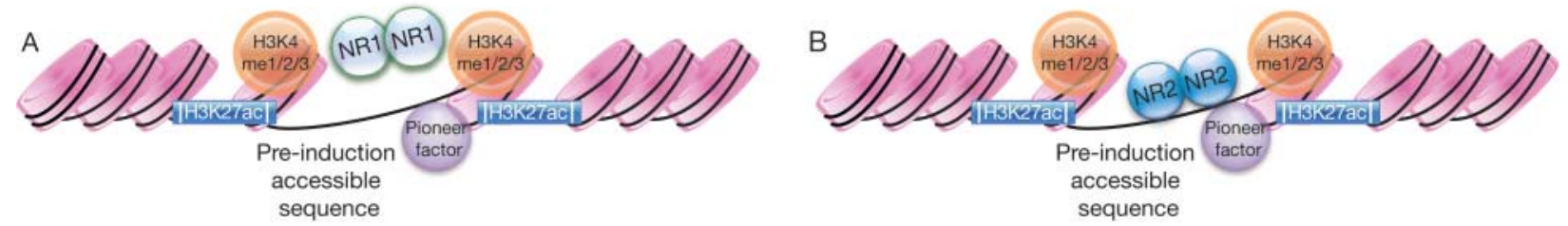

Chromatin accessibility post-induction

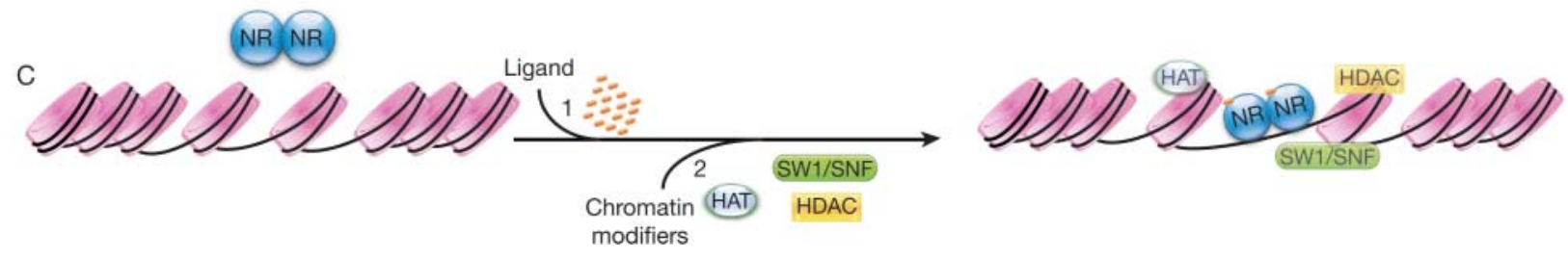

Figure 1

Schematic representation of nuclear receptors and chromatin accessibility. Nuclear receptors bind to responsive elements present in the DNA with different mechanisms. Chromatin accessibility and histone modifications contribute to NR binding via regulatory element bookmarking before ligands mediate activation (A). In some instances, NRs bind even in the

studies considering a few loci of GR-bound chromatin found some sites to be constitutively accessible using DNase I hypersensitivity site (DHS) assays and others to be remodelled upon ligand stimulation (John et al. 2008). However, a follow-up genome-wide screen using DHS assays coupled with next-generation sequencing (DHSseq) revealed that the majority (95\%) of GR binding occurs at pre-induction accessible sequences. These data demonstrate that chromatin accessibility can pre-select regulatory elements for GR binding. Adult cells present unique accessibility profiles (Thurman et al. 2012), suggesting that cell type-specific effects of NR activation could be partly mediated by the chromatin topology (John et al. 2008).

Nucleosome occupancy plays a different role in the context of AR binding at enhancers. After stimulation with dihydrotestosterone (DHT), He et al. (2012) observed the destabilization of a central nucleosome while the flanking nucleosomes remained occupied. In agreement with this, the central nucleosome is built around a modified histone protein called H2.A.Z, normally associated with fragile nucleosomes (Jin et al. 2009). Another study confirmed and expanded these observations and described a significant correlation between changes in DHS and AR-mediated transcription, suggesting that AR binding relieves nucleosome occupancy and potentially increases access for collaborating factors (Tewari et al. 2012). However, a later report suggested an intermediate model in which enhancers recruiting $\mathrm{AR}$ are in a stable equilibrium between absence of ligands while in complex with other proteins (B). Upon ligand activation, several NRs can guide further modifications of the chromatin landscape by recruiting histone modifiers and chromatin-remodelling complexes (C).

nucleosome occupancy and nucleosome-free state in uninduced cells. Androgen treatment then destabilizes this equilibrium in favour of the more accessible nucleosome-free state (Andreu-Vieyra et al. 2011).

The situation is less clear-cut for ER $\alpha$. Using formaldehyde-assisted isolation of regulatory element (FAIRE) assays, a technique that allows enrichment of nucleosome-depleted regions (Giresi et al. 2007), Hurtado et al. (2010) reported that a substantial amount of ER $\alpha$ can bind to more compacted chromatin regions. More importantly, they found that a significant proportion of accessible sites are present before oestrogen induction and they can recruit ER $\alpha$ (Hurtado et al. 2010). Identical conclusions can be drawn from a study that profiled chromatin accessibility before and after oestradiol (E2) stimulation, again using FAIRE assays (Joseph et al. 2010). These data are in substantial agreement with a more recent work that profiled $\mathrm{ER} \alpha$ chromatin accessibility using DHS assays (He et al. 2012). In addition, it was noted that ER $\alpha$ binding that leads to a substantial increase in chromatin accessibility clusters closer to oestrogen-responsive genes, suggesting that basal accessibility state can be further modified (discussed below, He et al. (2012)).

\section{Chromatin accessibility post-induction}

In the case of ligand-mediated DNA binding, nucleosome remodelling appears to continue even if the chromatin is

Published by Bioscientifica Ltd 
already in an accessible structure (He et al. 2012). Postinduction remodelling may have functional consequences for NR crosstalk. The assisted loading model predicts that binding of a NR may increase the chances of binding of a second NR via chromatin remodelling (Stratmann \& Schibler 2011). ER $\alpha$ directly or indirectly recruits several chromatin-remodelling complexes on the chromatin after oestrogen stimulation (Belandia et al. 2002, Jeong et al. 2009). Similarly, GR is associated with SWI/SNF complexes, proteins involved in ATP-mediated nucleosome remodelling (reviewed elsewhere, King et al. (2012)). Accordingly, GR activation using dexamethasone can increase binding of E2-induced $\mathrm{ER} \alpha$ at proximal chromatin locations (Voss et al. 2011, Miranda et al. 2013). Very similar observations were made with regard to the PR (Grøntved \& Hager 2012). Furthermore, another recent report has identified local interactions between $\mathrm{ER} \alpha$ and LRH1 (Lai et al. 2013). Depletion of LRH1 was found to cause decreased $\mathrm{ER} \alpha$ binding, while LRH1 overexpression was found to facilitate $\mathrm{ER} \alpha$ recruitment in the absence of $\mathrm{ER} \alpha$ protein levels changes, again supporting the notion of assisted loading. These data are consistent with the transient nature of the interaction of NRs with the chromatin. Indeed, ER $\alpha$ and the molecular machinery that accompanies ER $\alpha$ binding can contact the chromatin at relatively predictable intervals in synchronized MCF7 cells (Métivier et al. 2003, 2008, Reid et al. 2003). Although speculative, it is conceivable that activated NRs could also influence binding of other TFs. Collectively, these data highlight the importance of chromatin accessibility in dictating NR binding and how NRs modulate postinduction remodelling processes.

\section{Induction-independent}

Ligand-mediated activation does not always lead to chromatin binding. For example, several NRs are constitutively bound to the chromatin even in the absence of ligands. While there is evidence for agonist-dependent changes in binding of some hormone NRs to chromatin (as described above), the influence of agonist binding on DNA occupancy for metabolic NRs is complex and not fully understood. ChIP-seq analysis of mouse liver chromatin for FXR-binding sites revealed that the majority are located in distal intergenic regions or introns and fewer sites are localized in more proximal promoter regions (Chong et al. 2010). The high distribution of binding sites within intergenic and intronic regions is consistent with similar reports for other steroid and metabolic NRs, including PPAR $\gamma$ (Lefterova et al. 2008, Nielsen et al.
2008), ER $\alpha$ (Carroll et al. 2005) and AR (Bolton et al. 2007). Chong et al. (2010) found no statistically significant difference in genome-wide binding of FXR in the livers of a control group fed a normal chow diet vs a group fed chow supplemented with GW4064, the potent synthetic FXR agonist, suggesting that FXR binding is unaffected by ligand stimulation. These data are in substantial agreement with another genome-wide FXR binding study carried out in WT and obese mice, revealing a ligandindependent co-occupancy of FXR and RXR (Lee et al. 2012). The same pattern was observed in another genomewide binding site study, in mouse liver and intestine, where it was shown that FXR was already bound to its own REs in the regulatory regions of FXR target genes (Thomas et al. 2010). Although further studies need to be carried out, and different ligands studied, these results support the concept that metabolic NRs are bound to the DNA regardless of the presence of the ligand at accessible regulatory elements.

However, it is important to underline that these data might also be influenced by the basal FXR activation by bile acids, the FXR endogenous ligands. Nevertheless, the binding intensity was found to be boosted upon treatment with GW4064, in agreement with other in vitro studies in a liver cell line, HepG2, where it was shown that FXR binds to its REs weakly in the absence of ligands, and this binding is increased upon ligand treatment (Rizzo et al. 2005, Fang et al. 2008). Once again, this effect might be due to a ligand-switch effect, and it would be interesting to dissect the binding patterns of FXR upon treatment with natural ligands. Noteworthily, as pointed out by Chong et al. (2010), although bioinformatics analysis revealed over 1.7 million sites in the mouse genome matching the canonical FXR-REs, a very small percentage $(<0.1 \%)$ were shown to be occupied by FXR in their study. These results further support the idea that NRs are able to bind to their REs, although RE specificity is not sufficient. To achieve fully efficient NR-DNA binding, specific conditions are needed, including specific nucleosome positioning and epigenetic modifications able to alter chromatin structure and DNA accessibility.

\section{Histone post-translational modifications and their role in NR recruitment}

Epigenetic modifications have a well-characterized function during normal development where they bookmark regulatory elements to maintain heritable gene expression (Bernstein et al. 2006, Christophersen \& Helin 2010, Ernst \& Kellis 2010, Heinz et al. 2010, Ernst et al. 2011,

Published by Bioscientifica Ltd. 
Zhu et al. 2013). Only recently have we started to understand the relationship between histone modifications and NR activity. Several studies have shown direct interactions between the activation of NRs and the remodelling of chromatin through histone modifications. Analogously to chromatin remodelling, histone modifications play different roles and can be divided into pre-induction and post-induction.

\section{Pre-induction histone modifications}

Regulatory elements are characterized by an epigenetic grammar where combinatorial patterns of epigenetic modifications are associated with active, poised or inactive promoters and enhancers (Ernst \& Kellis 2010, Heinz et al. 2010, Ernst et al. 2011). For example, active enhancers are commonly marked by histone H3 lysine K4 mono- and/or dimethylation (H3K4me1/2) (Lupien et al. 2008, Ernst \& Kellis 2010). On the other hand, nucleosomes near the transcription start sites of active promoters are enriched with histone $\mathrm{H} 3$ lysine $\mathrm{K} 4$ trimethylation (H3K4me3; Bernstein et al. 2006, Thurman et al. 2012). NRs, similar to many other TFs, interpret the chromatin to find their cognate binding sequences (Magnani \& Lupien 2013). Therefore, preloaded epigenetic modifications can contribute to the reduction of the number of potential binding sites by 'flagging' active regulatory elements. For example, Lupien et al. (2008) found that binding of sex steroid NRs ER $\alpha$ and AR significantly correlated with H3K4me2 patterns in breast and prostate cancer cell lines respectively. As expected, breast and prostate cells are characterized by markedly different H3K4me2 histone mark layouts in agreement with cell type specificity of enhancer elements (Ernst et al. 2011, Zhu et al. 2013). The H3K4me2 as well as the H4K4me1 signal does not change in response to oestrogen stimulation in breast cancer cells (Lupien et al. 2008, Joseph et al. 2010, Magnani et al. 2011a), suggesting that histone methylation is independent of and precedes ER $\alpha$ binding. Similarly, in prostate cancer cells, H3K4me1/2 is found at active enhancers capable of recruiting AR before DHT stimulation in support of its role as a bookmarking modification (Wang et al. 2009). Limited functional studies assessing the effect of H3K4me removal on ER $\alpha$ signalling (Lupien et al. 2008, Magnani et al. 2011a) using overexpression of a histone lysine (K)-specific demethylase 1 (LSD1) indeed found a significant loss in ER $\alpha$ binding.

Interaction between epigenetic modification and NR binding is in some cases mediated by a group of proteins called pioneer factors (Magnani et al. 2011b, Zaret \&
Carroll 2011, Magnani \& Lupien 2013). Pioneer factors are a functionally defined family of proteins, including structurally unrelated TFs, capable of binding compacted chromatin (for extensive reviews, see Magnani et al. 2011b, Zaret \& Carroll 2011). These factors can relieve chromatin compaction during lineage commitment, to maintain accessibility at cell type-specific enhancers (Cirillo \& Zaret 1999). Pioneer factors can also act as molecular beacons for other TFs; for example, the forkhead family members FoxD3 and FoxA1 mark the liverspecific Alb1 enhancer starting from early embryonic development, preceding C/EBP, Ey and NFF1 binding and Alb1 expression (Zaret et al. 2008). Similarly, the homeobox pre-B-cell leukaemia transcription factor (PBX1) was found to precede MyoD recruitment during muscle development (Berkes et al. 2004). Accumulating evidence suggests that pioneer factors are preloaded on the chromatin at ER $\alpha$-recruiting regulatory elements before ligand activation and contribute to increased chromatin accessibility (Jozwik \& Carroll 2012). Depletion of pioneer factors including FOXA1 and PBX1 has a significant negative impact on ER $\alpha$-chromatin interaction (Lupien et al. 2008, Magnani et al. 2011a). It is not clear whether all NRs are associated with these proteins; however, it appears that different NRs share pioneer factors as in the case of $\mathrm{ER} \alpha, \mathrm{AR}$ and retinoic acid receptor gamma (RAR $\gamma$ ) and the pioneer factors FoxA1 and the trans-acting T-cell-specific transcription factor (GATA3) (Lupien et al. 2008, Hua et al. 2009). Pioneer factors lack protein domains typically interacting with modified histones (e.g. bromo- or cromodomains), and although some data suggest that pioneer factors can recognize specific histone modifications (Lupien et al. 2008, Magnani et al. 2011a), more studies are needed to establish the exact epigeneticpioneer factor-NR hierarchy (Magnani \& Lupien 2013).

\section{Post-induction histone modifications}

Upon ligand binding, ER $\alpha$ recruits a large cohort of accessory proteins as co-activators and co-repressors (O'Malley \& Kumar 2009, Mohammed et al. 2013). Interestingly, several chromatin modifiers belong to this class, including the histone acetyl transferase (HAT) p300 (Kraus \& Kadonaga 1998), arginine methyltransferase CARM1 (Lee et al. 2005), histone deacetylase HDAC2 (Mohammed et al. 2013) and histone demethylase KDM1A (aka LSD1) (Hu et al. 2008). Similarly, the H3K9me3 histone demethylase KDM3A is recruited by AR and PPAR $\gamma$ at NRREs (Yamane et al. 2006, Tateishi et al. 2009). There is a functional significance in HAT recruitment to the

Published by Bioscientifica Ltd. 
chromatin as acetylation of histones destabilizes the nucleosome structure by neutralizing the basic charge of the lysine (Yamane et al. 2006, Tateishi et al. 2009). In addition, acetylated lysine acts as molecular bait for bromodomain-containing proteins, including SWI/SNF chromatin-remodelling complexes, another group of NR co-factors (Trotter \& Archer 2008). Not surprisingly, chromatin remodellers and HAT proteins seem to trail very closely $\mathrm{ER} \alpha$ binding dynamics in synchronized cells stimulated with E2 (Métivier et al. 2003).

Histone-modifying proteins also interact with other NRs. Known interactors of GR include HDAC2 (Ito et al. 2000), HDAC1 (Qiu et al. 2011) and CBP/p300 (Pfitzner et al. 1998). Assembly of such multi-tasking complexes is compatible with the dual roles of NRs as activators and repressors. It is also likely that co-activator/co-repressors are cell type specific, considering the diverse number of cellular processes controlled by NRs.

As described for hormone NRs, once activated by its own natural ligands (bile acids), FXR recruits a number of co-activator complexes able to remodel the chromatin structure and facilitate the assembly of the transcriptional machinery to activate target gene expression. Ananthanarayanan et al. (2004) demonstrated with ChIP assay experiments that upon ligand binding, a simultaneous increase in FXR and CARM1 occupation occurs at the FXR target BSEP (ABCB11) (bile salt export pump) gene promoter. This binding was found to correspond with increased deposition of Arg-17 methylation and Lys-9 acetylation of histone $\mathrm{H} 3$ within the FXREs of BSEP, leading to increased BSEP gene transactivation. Furthermore, FXR can be methylated by Set7/9 within its hinge region at lysine-206. ChIP assays demonstrated the recruitment of Set7/9 and the presence of the associated H3K4 monomethylation activation mark at the loci of two of the known FXR hepatic targets, the small heterodimer partner NROB2 (SHP) and BSEP. This significantly enhanced the transcription of these two FXR target genes (Balasubramaniyan et al. 2012). Similar data for AR (Ko et al. 2011) and ER (Subramanian et al. 2008) indicate that this mechanism could also possibly stabilize FXR and promote its interaction with its heterodimerization partner RXR and the FXRE (Balasubramaniyan et al. 2012). Furthermore, recruitment of chromatin-remodelling proteins and NR-dependent gene transcription is a very dynamic process and different co-regulators and chromatin-remodelling proteins can occupy different REs of the same NR. In the hepatic FXR/SHP pathway, FXR senses elevated intrahepatic bile acid levels and indirectly suppresses the expression of the key-limiting enzyme of the bile acid synthesis pathway, CYP7A1, via SHP. Chromatin immunoprecipitation and chromatin remodelling studies in both HepG2 cells and mouse liver have shown that upon treatment with FXR agonists, the transcription activator Brg-1 is recruited to the SHP promoter and it interacts with FXR, resulting in accessible chromatin, thereby enhancing FXR-dependent transactivation of SHP. On the other hand, Brm is recruited to both SHP and CYP7A1 promoters, resulting in inactive, inaccessible chromatin (Miao et al. 2009). This indicates that chromatin remodellers Brm and Brg-1 have distinct functions in the regulation of two key genes within a single physiological pathway, by differentially modulating accessibility at SHP- and FXR-regulatory elements. In summary, these data demonstrate how NR binding facilitates the deposition of histone modifications, transiently altering the epigenetic profile of regulatory elements while locally increasing chromatin accessibility for the transcriptional machinery.

\section{Epigenetic modification contributes to stimulus-specific activation of regulatory elements}

NRs respond to a large array of molecules of diverse nature. Additionally, individual NRs can be promiscuous in terms of ligands. For example, metabolic NRs participate in complex, overlapping transcriptional regulation networks involving metabolic homoeostasis. Some of these receptors, such as the pregnane $\mathrm{X}$ receptor (PXR) and the constitutive androstane receptor (CAR), are promiscuous with respect to the structurally wide range of ligands that act as agonists. In fact, they can bind to metabolites that are also ligands for other NRs, such as bile acids or steroid hormones and others (Kliewer \& Willson 2002). This could be due to the presence of multiple LBDs, a very large binding pocket, or a binding site with flexibility to alter size and shape depending on the size of the ligand (reviewed in Krasowski et al. (2011)). In this context, the ER $\alpha$ has been the object of a substantial amount of work considering its role in breast cancer (Ali et al. 2011). ER $\alpha$ binding localization (its cistrome) has a significant impact on gene expression (Krum et al. 2008). Importantly, the ER $\alpha$ cistrome partially varies dependent on the type of ligand. Tamoxifen is one of the key molecules used in the treatment of breast cancer (Jordan 2003). Tamoxifen competes with $\mathrm{E} 2$ for the LBD of ER $\alpha$ and imparts a specific tridimensional structure not compatible with the recruitment of co-activators, at least in some tissues (Shang \& Brown 2002). Recent evidence suggests that tamoxifen

Published by Bioscientifica Ltd. 
alters the ER $\alpha$-DNA binding profile (Welboren et al. 2009). In agreement, cells that acquire resistance to tamoxifen recruit $\mathrm{ER} \alpha$ at a distinct set of loci compared with that of non-resistant cells (Ross-Innes et al. 2012). ER $\alpha$ can also be activated via growth factor-mediated phosphorylation induced by, for example, tyrosine kinase receptors such as the epidermal growth factor receptor (Kato et al. 1995). Genes regulated by phosphorylated ER $\alpha$ are distinct from oestrogen-responsive genes (Lupien et al. 2010). Importantly, oestrogen and EGF can induce ER $\alpha$ recruitment at three classes of enhancers: enhancers bound with stimulation with either oestrogen or EGF, enhancers bound exclusively following oestrogen treatment and enhancers bound exclusively following EGF treatment. These data are in agreement with ligand-specific NR binding (Lupien et al. 2010). However, the first class of regulatory elements (e.g. recruiting ER $\alpha$ in response to both stimuli) still exhibits a ligand-specific response as transcription is induced by only one ligand. This apparent contradiction is resolved taking into account $\mathrm{ER} \alpha$-mediated post-induction epigenetic modifications. Indeed, a fraction of these shared sites acquire stimulus-specific histone acetylation (H3K18ac; Lupien et al. 2010) and correlate with EGF- or oestrogenregulated genes. A recent study probing different classes of $\mathrm{ER} \alpha$ ligands has demonstrated that very minute changes in the chemical structure have significant effects on ER $\alpha$-regulated cellular processes such as proliferation (Srinivasan et al. 2013). These results were observed even in response to different allosteric interactions of the same ligand (Srinivasan et al. 2013). Although the ER $\alpha$ cistrome was not assessed, it is conceivable that each ligand induces topologically different binding events.

\section{Functional role of non-coding RNA in NR signalling}

We have previously mentioned that a large class of NRs exhibit a significant tendency towards binding enhancers (Kittler et al. 2013). Recent work pioneered by studies on $\mathrm{X}$-chromosome inactivation has highlighted a central role for long non-coding RNAs (lncRNAs) in epigenetic silencing and enhancer activation (Calabrese et al. 2012). Enhancer RNAs (eRNAs) are a class of lncRNAs with a potential role in the mediation of epigenetic modifications as well as interactions with TFs (Gupta et al. 2010, Kogo et al. 2011, Calabrese et al. 2012). Enhancer RNAs are typically bidirectional short RNAs transcribed by RNA polymerase II and centred around epigenetically defined enhancer elements (H3K4me1/2 and H3K27ac; Gupta et al. 2010, Kim et al. 2010, Kogo et al. 2011). They have been implicated in several molecular processes including polycomb-mediated repression (Tsai et al. 2010), metastatic progression (Gupta et al. 2010) and enhancer activity (Orom \& Shiekhattar 2011). Nonetheless, only recently, scientists have been able to elucidate their functional role partly through the use of NR-dependent cell lines (Orom \& Shiekhattar 2011, Li et al. 2013). ER binding is thought to promote enhancer-promoter looping to activate the transcriptional machinery at target genes (Perillo et al. 2008, Fullwood et al. 2009, Li et al. 2012, 2013). The Rosenfeld group has described a strong relationship between E2-ER $\alpha$-induced eRNA production and gene regulation (Li et al. 2013). Using siRNA and locked nucleic acid antisense oligonucleotides, the group was able to show that eRNA disruption suppresses E2-ER $\alpha$-mediated transcription by destabilizing long-distance interactions between promoters and enhancers (Li et al. 2013). The production of eRNAs substantially correlates with numerous markers of enhancer activation, including post-induction epigenetic modifications and increased chromatin accessibility (Hah et al. 2013). Interestingly, eRNA production does not seem to influence pre-induction histone modifications such as H3K4me1 and H3K4me3 (Hah et al. 2013). However, Hah et al. (2013) suggest that eRNA production may be occurring after the assembly of the transcriptional machinery on the chromatin and is decoupled by promoter-enhancer interaction. While we are just beginning to understand eRNAs, their interaction with NRs seems to be conserved as demonstrated by orphan NRs Rev-ERB $\alpha$ and Rev-ERB $\beta$. In this case, Rev-Erb receptors function as strong repressors by suppressing eRNA transcription at lineage-specific enhancers (Lam et al. 2013). Altogether, these data suggest that NR activity at enhancers is far more complex that initially postulated.

\section{Future directions}

NRs have been studied extensively for over 30 years; nevertheless, we are still gathering new information about the way they function. Several aspects are yet to be defined, including how NRs cooperate physically and mechanistically with each other and the DNA structure. For example, in hormone-dependent cancers, it will be crucial to establish the role of understudied NRs and understand whether they could replace the classical sex hormone receptors once anti-cancer drugs have targeted $\mathrm{ER} \alpha$ and AR. It will also be important to determine the role of unliganded NRs in development as well as disease. An intriguing study has found that unliganded PR forms a repressor complex with a non-coding RNA and several

Published by Bioscientifica Ltd. 
epigenetic silencers including histone demethylases LSD1, KDM5B and histone deacetylases HDAC1/2 (Vicent et al. 2013). In other words, unactivated PR maintains repressed chromatin structures at progesterone target gene enhancers, while the epigenetic landscape is reversed upon the interaction of PR with its ligand (Vicent et al. 2013). These data further highlight the complex interaction between non-coding RNA, epigenetic modifications, NRs and transcription. More questions concerning NR binding topology would need an answer, such as how heterogeneous is the binding in normal and diseased tissues and how targeted therapies can alter NR binding profiles. Considering that enhancer elements are inherently variable between individuals (Kasowski et al. 2013), it is reasonable to expect that NRs will also target different regions in different patients. Indeed, a recent study that profiled ER $\alpha$ binding in breast cancer patients has found little consensus between individuals for most of the ER $\alpha$ binding regions (Ross-Innes et al. 2012). Furthermore, in a study of hepatic genomic binding of ligand-activated FXR in healthy and obese mice, Lee et al. (2012) demonstrated that almost $50 \%$ of the sites were unique to either healthy or obese mice and that the altered FXR binding led to direct repression of many of these unique targets. Finally, it has been shown that the H3K4me3 epigenetic mark, essential for the transactivation of a number of hepatic FXR target genes, is reduced at their FXREs in a mouse model of cholestasis (Ananthanarayanan et al. 2004, Lee et al. 2012). Whether this is a reflection of an intrinsic heterogeneity in the epigenetic landscape of diseased tissues still requires clarification.

Ultimately, in the last few years, there has been a surge in studies addressing the fundamental role of chromatin and epigenetics in directing transcription. The inducible nature of NRs and the study of their interaction with the DNA allow us to mechanistically explore the dynamic nature of transcription and how diseases alter TFchromatin crosstalk. Further understanding of these processes will contribute to the discovery of new relevant clinical implications (e.g. location-specific chromatin interactions as a prognostic factor) and the development of novel and more targeted treatments. Considering the importance of NRs in development, metabolism and disease and the high potential for pharmacological manipulation, we foresee new breakthroughs in the coming years.

\section{Declaration of interest}

The authors declare that there is no conflict of interest that could be perceived as prejudicing the impartiality of the review.
Funding

This work was supported by Imperial Junior Research Fellowships to $L M$ and $R M$ M.

\section{Acknowledgements}

The authors thank Dr Charlotte Bevan and Dr Simak Ali for critical reading of the manuscript.

\section{References}

Ali S, Buluwela L \& Coombes RC 2011 Antiestrogens and their therapeutic applications in breast cancer and other diseases. Annual Review of Medicine 62 217-232. (doi:10.1146/annurev-med-052209-100305) Ananthanarayanan M, Li S, Balasubramaniyan N, Suchy FJ \& Walsh MJ 2004 Ligand-dependent activation of the farnesoid X-receptor directs arginine methylation of histone H3 by CARM1. Journal of Biological Chemistry 279 54348-54357. (doi:10.1074/jbc.M410021200)

Andreu-Vieyra C, Lai J, Berman BP, Frenkel B, Jia L, Jones PA \& Coetzee GA 2011 Dynamic nucleosome-depleted regions at androgen receptor enhancers in the absence of ligand in prostate cancer cells. Molecular and Cellular Biology 31 4648-4662. (doi:10.1128/MCB.05934-11)

Bain DL, Heneghan AF, Connaghan-Jones KD \& Miura MT 2007 Nuclear receptor structure: implications for function. Annual Review of Physiology 69 201-220. (doi:10.1146/annurev.physiol.69.031905. 160308)

Balasubramaniyan N, Ananthanarayanan M \& Suchy FJ 2012 Direct methylation of FXR by Set7/9, a lysine methyltransferase, regulates the expression of FXR target genes. American Journal of Physiology. Gastrointestinal and Liver Physiology 302 G937-G947. (doi:10.1152/ ajpgi.00441.2011)

Belandia B, Orford RL, Hurst HC \& Parker MG 2002 Targeting of SWI/SNF chromatin remodelling complexes to estrogen-responsive genes. $E M B O$ Journal 21 4094-4103. (doi:10.1093/emboj/cdf412)

Berkes CA, Bergstrom DA, Penn BH, Seaver KJ, Knoepfler PS \& Tapscott SJ 2004 Pbx marks genes for activation by MyoD indicating a role for a homeodomain protein in establishing myogenic potential. Molecular Cell 14 465-477. (doi:10.1016/S1097-2765(04)00260-6)

Bernstein BE, Mikkelsen TS, Xie X, Kamal M, Huebert DJ, Cuff J, Fry B, Meissner A, Wernig M, Plath K et al. 2006 A bivalent chromatin structure marks key developmental genes in embryonic stem cells. Cell 125 315-326. (doi:10.1016/j.cell.2006.02.041)

Bolton EC, So AY, Chaivorapol C, Haqq CM, Li H \& Yamamoto KR 2007 Cell- and gene-specific regulation of primary target genes by the androgen receptor. Genes and Development 21 2005-2017. (doi:10.1101/ gad.1564207)

Bourguet W, Germain P \& Gronemeyer H 2000 Nuclear receptor ligandbinding domains: three-dimensional structures, molecular interactions and pharmacological implications. Trends in Pharmacological Sciences 21 381-388. (doi:10.1016/S0165-6147(00)01548-0)

Calabrese JM, Sun W, Song L, Mugford JW, Williams L, Yee D, Starmer J, Mieczkowski P, Crawford GE \& Magnuson T 2012 Site-specific silencing of regulatory elements as a mechanism of X inactivation. Cell $\mathbf{1 5 1}$ 951-963. (doi:10.1016/j.cell.2012.10.037)

Carroll JS, Liu XS, Brodsky AS, Li W, Meyer CA, Szary AJ, Eeckhoute J, Shao W, Hestermann EV, Geistlinger TR et al. 2005 Chromosome-wide mapping of estrogen receptor binding reveals long-range regulation requiring the forkhead protein FoxA1. Cell 122 33-43. (doi:10.1016/ j.cell.2005.05.008)

Chambon P 2005 The nuclear receptor superfamily: a personal retrospect on the first two decades. Molecular Endocrinology 19 1418-1428. (doi:10.1210/me.2005-0125) 
Chawla A, Boisvert WA, Lee CH, Laffitte BA, Barak Y, Joseph SB, Liao D, Nagy L, Edwards PA, Curtiss LK et al. 2001 A PPAR $\gamma$-LXR-ABCA1 pathway in macrophages is involved in cholesterol efflux and atherogenesis. Molecular Cell 7 161-171. (doi:10.1016/S1097-2765 (01)00164-2)

Chen D, Pace PE, Coombes RC \& Ali S 1999 Phosphorylation of human estrogen receptor $\alpha$ by protein kinase A regulates dimerization. Molecular and Cellular Biology 19 1002-1015.

Chong HK, Infante AM, Seo Y-K, Jeon T-I, Zhang Y, Edwards PA, Xie X \& Osborne TF 2010 Genome-wide interrogation of hepatic FXR reveals an asymmetric IR-1 motif and synergy with LRH-1. Nucleic Acids Research 38 6007-6017. (doi:10.1093/nar/gkq397)

Christophersen NS \& Helin K 2010 Epigenetic control of embryonic stem cell fate. Journal of Experimental Medicine 207 2287-2295. (doi:10.1084/ jem.20101438)

Cirillo LA \& Zaret KS 1999 An early developmental transcription factor complex that is more stable on nucleosome core particles than on free DNA. Molecular Cell 4 961-969. (doi:10.1016/S1097-2765 (00)80225-7)

ENCODE Project Consortium, Birney E, Stamatoyannopoulos JA, Dutta A, Guigó R, Gingeras TR, Margulies EH, Weng Z, Snyder M, Dermitzakis ET et al. 2007 Identification and analysis of functional elements in $1 \%$ of the human genome by the ENCODE pilot project. Nature $\mathbf{4 4 7} 799-816$. (doi:10.1038/nature05874)

ENCODE Project Consortium, Bernstein BE, Birney E, Dunham I, Green ED, Gunter C \& Snyder M 2012 An integrated encyclopedia of DNA elements in the human genome. Nature 489 57-74. (doi:10.1038/ nature11247)

Ernst J \& Kellis M 2010 Discovery and characterization of chromatin states for systematic annotation of the human genome. Nature Biotechnology 28 817-825. (doi:10.1038/nbt.1662)

Ernst J, Kheradpour P, Mikkelsen TS, Shoresh N, Ward LD, Epstein CB, Zhang X, Wang L, Issner R, Coyne M et al. 2011 Mapping and analysis of chromatin state dynamics in nine human cell types. Nature $\mathbf{4 7 3}$ 43-49. (doi:10.1038/nature09906)

Evans RM 2005 The nuclear receptor superfamily: a rosetta stone for physiology. Molecular Endocrinology 19 1429-1438. (doi:10.1210/me. 2005-0046)

Fang S, Tsang S, Jones R, Ponugoti B, Yoon H, Wu S-Y, Chiang C-M, Willson TM \& Kemper JK 2008 The p300 acetylase is critical for ligandactivated farnesoid X receptor (FXR) induction of SHP. Journal of Biological Chemistry 283 35086-35095. (doi:10.1074/jbc.M803531200)

Fondell JD, Ge H \& Roeder RG 1996 Ligand induction of a transcriptionally active thyroid hormone receptor coactivator complex. PNAS 93 8329-8333. (doi:10.1073/pnas.93.16.8329)

Fullwood MJ, Liu MH, Pan YF, Liu J, Xu H, Mohamed YB, Orlov YL, Velkov S, Ho A, Mei PH et al. 2009 An oestrogen-receptor- $\alpha$-bound human chromatin interactome. Nature 462 58-64. (doi:10.1038/nature08497)

Germain P, Staels B, Dacquet C, Spedding M \& Laudet V 2006 Overview of nomenclature of nuclear receptors. Pharmacological Reviews $\mathbf{5 8}$ 685-704. (doi:10.1124/pr.58.4.2)

Giguère V, Hollenberg SM, Rosenfeld MG \& Evans RM 1986 Functional domains of the human glucocorticoid receptor. Cell 46 645-652. (doi:10.1016/0092-8674(86)90339-9)

Gineste R, Sirvent A, Paumelle R, Helleboid S, Aquilina A, Darteil R, Hum DW, Fruchart J-C \& Staels B 2008 Phosphorylation of farnesoid $\mathrm{X}$ receptor by protein kinase $\mathrm{C}$ promotes its transcriptional activity. Molecular Endocrinology 22 2433-2447. (doi:10.1210/me.2008-0092)

Giresi PG, Kim J, McDaniell RM, Iyer VR \& Lieb JD 2007 FAIRE (formaldehyde-assisted isolation of regulatory elements) isolates active regulatory elements from human chromatin. Genome Research $\mathbf{1 7}$ 877-885. (doi:10.1101/gr.5533506)

Greene GL, Gilna P, Waterfield M, Baker A, Hort Y \& Shine J 1986 Sequence and expression of human estrogen receptor complementary DNA. Science 231 1150-1154. (doi:10.1126/science.3753802)
Gronemeyer H, Gustafsson J-A \& Laudet V 2004 Principles for modulation of the nuclear receptor superfamily. Nature Reviews. Drug Discovery 3 950-964. (doi:10.1038/nrd1551)

Grøntved L \& Hager GL 2012 Impact of chromatin structure on PR signaling: transition from local to global analysis. Molecular and Cellular Endocrinology 357 30-36. (doi:10.1016/j.mce.2011.09.006)

Gupta RA, Shah N, Wang KC, Kim J, Horlings HM, Wong DJ, Tsai M-C, Hung T, Argani P, Rinn JL et al. 2010 Long non-coding RNA HOTAIR reprograms chromatin state to promote cancer metastasis. Nature $\mathbf{4 6 4}$ 1071-1076. (doi:10.1038/nature08975)

Hah N, Murakami S, Nagari A, Danko CG \& Kraus WL 2013 Enhancer transcripts mark active estrogen receptor binding sites. Genome Research 23 1210-1223. (doi:10.1101/gr.152306.112)

He HH, Meyer CA, Chen MW, Jordan VC, Brown M \& Liu XS 2012 Differential DNase I hypersensitivity reveals factor-dependent chromatin dynamics. Genome Research 22 1015-1025. (doi:10.1101/ gr.133280.111)

Heinz S, Benner C, Spann N, Bertolino E, Lin YC, Laslo P, Cheng JX, Murre C, Singh H \& Glass CK 2010 Simple combinations of lineagedetermining transcription factors prime cis-regulatory elements required for macrophage and B cell identities. Molecular Cell $\mathbf{3 8}$ 576-589. (doi:10.1016/j.molcel.2010.05.004)

Heldring N, Isaacs GD, Diehl AG, Sun M, Cheung E, Ranish JA \& Kraus WL 2011 Multiple sequence-specific DNA-binding proteins mediate estrogen receptor signaling through a tethering pathway. Molecular Endocrinology 25 564-574. (doi:10.1210/me.2010-0425)

Hollenberg SM, Weinberger C, Ong ES, Cerelli G, Oro A, Lebo R, Thompson EB, Rosenfeld MG \& Evans RM 1985 Primary structure and expression of a functional human glucocorticoid receptor cDNA. Nature 318 635-641. (doi:10.1038/318635a0)

Hu Q, Kwon Y-S, Nunez E, Cardamone MD, Hutt KR, Ohgi KA, Garcia-Bassets I, Rose DW, Glass CK, Rosenfeld MG et al. 2008 Enhancing nuclear receptor-induced transcription requires nuclear motor and LSD1-dependent gene networking in interchromatin granules. PNAS 105 19199-19204. (doi:10.1073/pnas.0810634105)

Hua S, Kittler R \& White KP 2009 Genomic antagonism between retinoic acid and estrogen signaling in breast cancer. Cell 137 1259-1271. (doi:10.1016/j.cell.2009.04.043)

Hurtado A, Holmes KA, Ross-Innes CS, Schmidt D \& Carroll JS 2010 FOXA1 is a key determinant of estrogen receptor function and endocrine response. Nature Genetics 43 27-33. (doi:10.1038/ng.730)

Ito K, Barnes PJ \& Adcock IM 2000 Glucocorticoid receptor recruitment of histone deacetylase 2 inhibits interleukin-1ß-induced histone $\mathrm{H} 4$ acetylation on lysines 8 and 12. Molecular and Cellular Biology 20 6891-6903. (doi:10.1128/MCB.20.18.6891-6903.2000)

Jeong KW, Lee Y-H \& Stallcup MR 2009 Recruitment of the SWI/SNF chromatin remodeling complex to steroid hormone-regulated promoters by nuclear receptor coactivator flightless-I. Journal of Biological Chemistry 284 29298-29309. (doi:10.1074/jbc.M109.037010)

Jin C, Zang C, Wei G, Cui K, Peng W, Zhao K \& Felsenfeld G 2009 H3.3/H2A.Z double variant-containing nucleosomes mark 'nucleosome-free regions' of active promoters and other regulatory regions. Nature Genetics 41 941-945. (doi:10.1038/ng.409)

John S, Sabo PJ, Johnson TA, Sung M-H, Biddie SC, Lightman SL, Voss TC, Davis SR, Meltzer PS, Stamatoyannopoulos JA et al. 2008 Interaction of the glucocorticoid receptor with the chromatin landscape. Molecular Cell 29 611-624. (doi:10.1016/j.molcel.2008.02.010)

Jordan VC 2003 Tamoxifen: a most unlikely pioneering medicine. Nature Reviews. Drug Discovery 2 205-213. (doi:10.1038/nrd1031)

Joseph R, Orlov YL, Huss M, Sun W, Kong SL, Ukil L, Pan YF, Li G, Lim M, Thomsen JS et al. 2010 Integrative model of genomic factors for determining binding site selection by estrogen receptor- $\alpha$. Molecular Systems Biology 6 456. (doi:10.1038/msb.2010.109)

Jozwik KM \& Carroll JS 2012 Pioneer factors in hormone-dependent cancers. Nature Reviews. Cancer 12 381-385. (doi:10.1038/nrc3263)

Published by Bioscientifica Ltd. 
Kasowski M, Kyriazopoulou-Panagiotopoulou S, Grubert F, Zaugg JB, Kundaje A, Liu Y, Boyle AP, Zhang QC, Zakharia F, Spacek DV et al. 2013 Extensive variation in chromatin states across humans. Science $\mathbf{3 4 2}$ 750-752. (doi:10.1126/science.1242510)

Kato S, Endoh H, Masuhiro Y, Kitamoto T, Uchiyama S, Sasaki H, Masushige S, Gotoh Y, Nishida E, Kawashima H et al. 1995 Activation of the estrogen receptor through phosphorylation by mitogen-activated protein kinase. Science 270 1491-1494. (doi:10.1126/science.270.5241. 1491)

Kim T-K, Hemberg M, Gray JM, Costa AM, Bear DM, Wu J, Harmin DA, Laptewicz M, Barbara-Haley K, Kuersten S et al. 2010 Widespread transcription at neuronal activity-regulated enhancers. Nature $\mathbf{4 6 5}$ 182-187. (doi:10.1038/nature09033)

King HA, Trotter KW \& Archer TK 2012 Chromatin remodeling during glucocorticoid receptor regulated transactivation. Biochimica et Biophysica Acta 1819 716-726. (doi:10.1016/j.bbagrm.2012.02.019)

Kininis M \& Kraus WL 2008 A global view of transcriptional regulation by nuclear receptors: gene expression, factor localization, and DNA sequence analysis. Nuclear Receptor Signaling 6 e005.

Kittler R, Zhou J, Hua S, Ma L, Liu Y, Pendleton E, Cheng C, Gerstein M \& White KP 2013 A comprehensive nuclear receptor network for breast cancer cells. Cell Reports 3 538-551. (doi:10.1016/j.celrep.2013.01.004)

Kliewer SA \& Willson TM 2002 Regulation of xenobiotic and bile acid metabolism by the nuclear pregnane $\mathrm{X}$ receptor. Journal of Lipid Research 43 359-364.

Ko S, Ahn J, Song CS, Kim S, Knapczyk-Stwora K \& Chatterjee B 2011 Lysine methylation and functional modulation of androgen receptor by Set 9 methyltransferase. Molecular Endocrinology 25 433-444. (doi:10.1210/ me.2010-0482)

Kogo R, Shimamura T, Mimori K, Kawahara K, Imoto S, Sudo T, Tanaka F, Shibata K, Suzuki A, Komune S et al. 2011 Long noncoding RNA HOTAIR regulates polycomb-dependent chromatin modification and is associated with poor prognosis in colorectal cancers. Cancer Research $\mathbf{7 1}$ 6320-6326. (doi:10.1158/0008-5472.CAN-11-1021)

Kouzarides T 2007 Chromatin modifications and their function. Cell 128 693-705. (doi:10.1016/j.cell.2007.02.005)

Krasowski MD, Ni A, Hagey LR \& Ekins S 2011 Evolution of promiscuous nuclear hormone receptors: LXR, FXR, VDR, PXR, and CAR. Molecular and Cellular Endocrinology 334 39-48. (doi:10.1016/j.mce.2010.06.016)

Kraus WL \& Kadonaga JT 1998 p300 and estrogen receptor cooperatively activate transcription via differential enhancement of initiation and reinitiation. Genes and Development 12 331-342. (doi:10.1101/gad. 12.3.331)

Krum SA, Miranda-Carboni GA, Lupien M, Eeckhoute J, Carroll JS \& Brown M 2008 Unique ER $\alpha$ cistromes control cell type-specific gene regulation. Molecular Endocrinology 22 2393-2406. (doi:10.1210/me. 2008-0100)

Lai C-F, Flach KD, Alexi X, Fox SP, Ottaviani S, Thiruchelvam PTR, Kyle FJ, Thomas RS, Launchbury R, Hua H et al. 2013 Co-regulated gene expression by oestrogen receptor $\alpha$ and liver receptor homolog- 1 is a feature of the oestrogen response in breast cancer cells. Nucleic Acids Research 41 10228-10240. (doi:10.1093/nar/gkt827)

Lam MTY, Cho H, Lesch HP, Gosselin D, Heinz S, Tanaka-Oishi Y, Benner C, Kaikkonen MU, Kim AS, Kosaka M et al. 2013 Rev-Erbs repress macrophage gene expression by inhibiting enhancer-directed transcription. Nature 498 511-515. (doi:10.1038/nature12209)

Lee Y-H, Coonrod SA, Kraus WL, Jelinek MA \& Stallcup MR 2005 Regulation of coactivator complex assembly and function by protein arginine methylation and demethylimination. PNAS 102 3611-3616. (doi:10.1073/pnas.0407159102)

Lee J, Seok S, Yu P, Kim K, Smith Z, Rivas-Astroza M, Zhong S \& Kemper JK 2012 Genomic analysis of hepatic farnesoid X receptor binding sites reveals altered binding in obesity and direct gene repression by farnesoid X receptor in mice. Hepatology 56 108-117. (doi:10.1002/ hep.25609)
Lefterova MI, Zhang Y, Steger DJ, Schupp M, Schug J, Cristancho A, Feng D, Zhuo D, Stoeckert CJ, Liu XS et al. 2008 PPAR $\gamma$ and C/EBP factors orchestrate adipocyte biology via adjacent binding on a genome-wide scale. Genes and Development 22 2941-2952. (doi:10.1101/gad.1709008)

Li G, Ruan X, Auerbach RK, Sandhu KS, Zheng M, Wang P, Poh HM, Goh Y, Lim J, Zhang J et al. 2012 Extensive promoter-centered chromatin interactions provide a topological basis for transcription regulation. Cell 148 84-98. (doi:10.1016/j.cell.2011.12.014)

Li W, Notani D, Ma Q, Tanasa B, Nunez E, Chen AY, Merkurjev D, Zhang J, Ohgi K, Song X et al. 2013 Functional roles of enhancer RNAs for oestrogen-dependent transcriptional activation. Nature 498 516-520. (doi:10.1038/nature12210)

Lupien M, Eeckhoute J, Meyer CA, Wang Q, Zhang Y, Li W, Carroll JS, Liu XS \& Brown M 2008 FoxA1 translates epigenetic signatures into enhancer-driven lineage-specific transcription. Cell 132 958-970. (doi:10.1016/j.cell.2008.01.018)

Lupien M, Meyer CA, Bailey ST, Eeckhoute J, Cook J, Westerling T, Zhang X, Carroll JS, Rhodes DR, Liu XS et al. 2010 Growth factor stimulation induces a distinct $\operatorname{ER}(\alpha)$ cistrome underlying breast cancer endocrine resistance. Genes and Development 24 2219-2227. (doi:10.1101/gad. 1944810)

Magnani L \& Lupien M 2013 Chromatin and epigenetic determinants of estrogen receptor $\alpha$ (ESR1) signaling. Molecular and Cellular Endocrinology 382 633-641. (doi:10.1016/j.mce.2013.04.026)

Magnani L, Ballantyne EB, Zhang X \& Lupien M 2011a PBX1 genomic pioneer function drives $\mathrm{ER} \alpha$ signaling underlying progression in breast cancer. PLoS Genetics 7 e1002368. (doi:10.1371/journal.pgen. 1002368)

Magnani L, Eeckhoute J \& Lupien M 2011b Pioneer factors: directing transcriptional regulators within the chromatin environment. Trends in Genetics 27 465-474. (doi:10.1016/j.tig.2011.07.002)

Mangelsdorf DJ \& Evans RM 1995 The RXR heterodimers and orphan receptors. Cell 83 841-850. (doi:10.1016/0092-8674(95)90200-7)

Mangelsdorf DJ, Thummel C, Beato M, Herrlich P, Schütz G, Umesono K, Blumberg B, Kastner P, Mark M, Chambon P et al. 1995 The nuclear receptor superfamily: the second decade. Cell 83 835-839. (doi:10. 1016/0092-8674(95)90199-X)

Métivier R, Penot G, Hübner MR, Reid G, Brand H, Kos M \& Gannon F 2003 Estrogen receptor- $\alpha$ directs ordered, cyclical, and combinatorial recruitment of cofactors on a natural target promoter. Cell $\mathbf{1 1 5}$ 751-763. (doi:10.1016/S0092-8674(03)00934-6)

Métivier R, Gallais R, Tiffoche C, Le Péron C, Jurkowska RZ, Carmouche RP, Ibberson D, Barath P, Demay F, Reid G et al. 2008 Cyclical DNA methylation of a transcriptionally active promoter. Nature $\mathbf{4 5 2} 45-50$. (doi:10.1038/nature06544)

Miao J, Fang S, Lee J, Comstock C, Knudsen KE \& Kemper JK 2009 Functional specificities of Brm and Brg-1 Swi/Snf ATPases in the feedback regulation of hepatic bile acid biosynthesis. Molecular and Cellular Biology 29 6170-6181. (doi:10.1128/MCB.00825-09)

Miranda TB, Voss TC, Sung M-H, Baek S, John S, Hawkins M, Grøntved L, Schiltz RL \& Hager GL 2013 Reprogramming the chromatin landscape: interplay of the estrogen and glucocorticoid receptors at the genomic level. Cancer Research 73 5130-5139. (doi:10.1158/0008-5472.CAN13-0742)

Mohammed H, D'Santos C, Sérandour AA, Ali HR, Brown GD, Atkins A, Rueda OM, Holmes KA, Theodorou V, Robinson JLL et al. 2013 Endogenous purification reveals GREB1 as a key estrogen receptor regulatory factor. Cell Reports 3 342-349. (doi:10.1016/j.celrep.2013. 01.010)

Nielsen R, Pedersen TA, Hagenbeek D, Moulos P, Siersbaek R, Megens E, Denissov S, Børgesen M, Francoijs K-J, Mandrup S et al. 2008 Genomewide profiling of PPAR $\gamma:$ RXR and RNA polymerase II occupancy reveals temporal activation of distinct metabolic pathways and changes in RXR dimer composition during adipogenesis. Genes and Development 22 2953-2967. (doi:10.1101/gad.501108) 
Nuclear Receptors Nomenclature Committee 1999 A unified nomenclature system for the nuclear receptor superfamily. Cell 97 161-163. (doi:10.1016/S0092-8674(00)80726-6)

O'Malley BW \& Kumar R 2009 Nuclear receptor coregulators in cancer biology. Cancer Research 69 8217-8222. (doi:10.1158/0008-5472. CAN-09-2223)

Orom UA \& Shiekhattar R 2011 Long non-coding RNAs and enhancers. Current Opinion in Genetics \& Development 21 194-198. (doi:10.1016/ j.gde.2011.01.020)

Overington JP, Al-Lazikani B \& Hopkins AL 2006 How many drug targets are there? Nature Reviews. Drug Discovery 5 993-996. (doi:10.1038/ nrd2199)

Pascual G, Fong AL, Ogawa S, Gamliel A, Li AC, Perissi V, Rose DW, Willson TM, Rosenfeld MG \& Glass CK 2005 A SUMOylationdependent pathway mediates transrepression of inflammatory response genes by PPAR- $\gamma$. Nature 437 759-763. (doi:10.1038/ nature03988)

Perillo B, Ombra MN, Bertoni A, Cuozzo C, Sacchetti S, Sasso A, Chiariotti L, Malorni A, Abbondanza C \& Avvedimento EV 2008 DNA oxidation as triggered by H3K9me2 demethylation drives estrogen-induced gene expression. Science 319 202-206. (doi:10.1126/science.1147674)

Pfitzner E, Jähne R, Wissler M, Stoecklin E \& Groner B 1998 p300/CREBbinding protein enhances the prolactin-mediated transcriptional induction through direct interaction with the transactivation domain of Stat5, but does not participate in the Stat5-mediated suppression of the glucocorticoid response. Molecular Endocrinology 12 1582-1593. (doi:10.1210/me.12.10.1582)

Qiu Y, Stavreva DA, Luo Y, Indrawan A, Chang M \& Hager GL 2011 Dynamic interaction of HDAC1 with a glucocorticoid receptorregulated gene is modulated by the activity state of the promoter. Journal of Biological Chemistry 286 7641-7647. (doi:10.1074/jbc.M110. 185488)

Reid G, Hübner MR, Métivier R, Brand H, Denger S, Manu D, Beaudouin J, Ellenberg J \& Gannon F 2003 Cyclic, proteasome-mediated turnover of unliganded and liganded $\mathrm{ER} \alpha$ on responsive promoters is an integral feature of estrogen signaling. Molecular Cell 11 695-707. (doi:10.1016/ S1097-2765(03)00090-X)

Rizzo G, Renga B, Antonelli E, Passeri D, Pellicciari R \& Fiorucci S 2005 The methyl transferase PRMT1 functions as co-activator of farnesoid X receptor (FXR)/9-cis retinoid X receptor and regulates transcription of FXR responsive genes. Molecular Pharmacology 68 551-558. (doi:10.1124/mol.105.012104)

Ross-Innes CS, Stark R, Teschendorff AE, Holmes KA, Ali HR, Dunning MJ, Brown GD, Gojis O, Ellis IO, Green AR et al. 2012 Differential oestrogen receptor binding is associated with clinical outcome in breast cancer. Nature 481 389-393.

Sap J, Muñoz A, Damm K, Goldberg Y, Ghysdael J, Leutz A, Beug H \& Vennström B 1986 The c-erb-A protein is a high-affinity receptor for thyroid hormone. Nature 324 635-640. (doi:10.1038/324635a0)

Shang Y \& Brown M 2002 Molecular determinants for the tissue specificity of SERMs. Science 295 2465-2468. (doi:10.1126/science.1068537)

Srinivasan S, Nwachukwu JC, Parent AA, Cavett V, Nowak J, Hughes TS, Kojetin DJ, Katzenellenbogen JA \& Nettles KW 2013 Ligand-binding dynamics rewire cellular signaling via estrogen receptor- $\alpha$. Nature Chemical Biology 9 326-332. (doi:10.1038/nchembio.1214)

Stender JD, Kim K, Charn TH, Komm B, Chang KCN, Kraus WL, Benner C, Glass CK \& Katzenellenbogen BS 2010 Genome-wide analysis of estrogen receptor $\alpha$ DNA binding and tethering mechanisms identifies Runx1 as a novel tethering factor in receptor-mediated transcriptional activation. Molecular and Cellular Biology 30 3943-3955. (doi:10.1128/ MCB.00118-10)

Stratmann M \& Schibler U 2011 Transcription factor loading: please take my place! Cell 146 497-499. (doi:10.1016/j.cell.2011.07.037)

Subramanian K, Jia D, Kapoor-Vazirani P, Powell DR, Collins RE, Sharma D, Peng J, Cheng X \& Vertino PM 2008 Regulation of estrogen receptor $\alpha$ by the SET7 lysine methyltransferase. Molecular Cell 30 336-347. (doi:10.1016/j.molcel.2008.03.022)

Suganuma T \& Workman JL 2008 Crosstalk among histone modifications. Cell 135 604-607. (doi:10.1016/j.cell.2008.10.036)

Tateishi K, Okada Y, Kallin EM \& Zhang Y 2009 Role of Jhdm2a in regulating metabolic gene expression and obesity resistance. Nature 458 757-761. (doi:10.1038/nature07777)

Tewari AK, Yardimci GG, Shibata Y, Sheffield NC, Song L, Taylor BS, Georgiev SG, Coetzee GA, Ohler U, Furey TS et al. 2012 Chromatin accessibility reveals insights into androgen receptor activation and transcriptional specificity. Genome Biology 13 R88. (doi:10.1186/ gb-2012-13-10-r88)

Thomas AM, Hart SN, Kong B, Fang J, Zhong X-B \& Guo GL 2010 Genome-wide tissue-specific farnesoid $\mathrm{X}$ receptor binding in mouse liver and intestine. Hepatology 51 1410-1419. (doi:10.1002/hep.23450)

Thurman RE, Rynes E, Humbert R, Vierstra J, Maurano MT, Haugen E, Sheffield NC, Stergachis AB, Wang H, Vernot B et al. 2012 The accessible chromatin landscape of the human genome. Nature 489 75-82. (doi:10.1038/nature11232)

Trotter KW \& Archer TK 2008 The BRG1 transcriptional coregulator. Nuclear Receptor Signaling 6 e004.

Tsai M-C, Manor O, Wan Y, Mosammaparast N, Wang JK, Lan F, Shi Y, Segal E \& Chang HY 2010 Long noncoding RNA as modular scaffold of histone modification complexes. Science 329 689-693. (doi:10.1126/ science.1192002)

Tzagarakis-Foster C \& Privalsky ML 1998 Phosphorylation of thyroid hormone receptors by protein kinase A regulates DNA recognition by specific inhibition of receptor monomer binding. Journal of Biological Chemistry 273 10926-10932. (doi:10.1074/jbc.273.18.10926)

Vavassori P, Mencarelli A, Renga B, Distrutti E \& Fiorucci S 2009 The bile acid receptor FXR is a modulator of intestinal innate immunity. Journal of Immunology 183 6251-6261. (doi:10.4049/jimmunol. 0803978)

Vicent GP, Nacht AS, Font-Mateu J, Castellano G, Gaveglia L, Ballaré C \& Beato M 2011 Four enzymes cooperate to displace histone H1 during the first minute of hormonal gene activation. Genes and Development 25 845-862. (doi:10.1101/gad.621811)

Vicent GP, Nacht AS, Zaurin R, Font-Mateu J, Soronellas D, Le Dily F, Reyes D \& Beato M 2013 Unliganded progesterone receptor-mediated targeting of an RNA-containing repressive complex silences a subset of hormone-inducible genes. Genes and Development 27 1179-1197. (doi:10.1101/gad.215293.113)

Voss TC, Schiltz RL, Sung M-H, Yen PM, Stamatoyannopoulos JA, Biddie SC, Johnson TA, Miranda TB, John S \& Hager GL 2011 Dynamic exchange at regulatory elements during chromatin remodeling underlies assisted loading mechanism. Cell 146 544-554. (doi:10.1016/j.cell. 2011.07.006)

Walter P, Green S, Greene G, Krust A, Bornert JM, Jeltsch JM, Staub A, Jensen E, Scrace G \& Waterfield M 1985 Cloning of the human estrogen receptor cDNA. PNAS 82 7889-7893. (doi:10.1073/pnas.82.23.7889)

Wang Q, Li W, Zhang Y, Yuan X, Xu K, Yu J, Chen Z, Beroukhim R, Wang H, Lupien $M$ et al. 2009 Androgen receptor regulates a distinct transcription program in androgen-independent prostate cancer. Cell 138 245-256. (doi:10.1016/j.cell.2009.04.056)

Wärnmark A, Treuter E, Wright APH \& Gustafsson J-A 2003 Activation functions 1 and 2 of nuclear receptors: molecular strategies for transcriptional activation. Molecular Endocrinology 17 1901-1909. (doi:10.1210/me.2002-0384)

Welboren W-J, van Driel MA, Janssen-Megens EM, van Heeringen SJ, Sweep FC, Span PN \& Stunnenberg HG 2009 ChIP-Seq of ER $\alpha$ and RNA polymerase II defines genes differentially responding to ligands. $E M B O$ Journal 28 1418-1428. (doi:10.1038/emboj.2009.88)

Whyte WA, Orlando DA, Hnisz D, Abraham BJ, Lin CY, Kagey MH, Rahl PB, Lee TI \& Young RA 2013 Master transcription factors and mediator establish super-enhancers at key cell identity genes. Cell 153 307-319. (doi:10.1016/j.cell.2013.03.035) 
Willis S \& Griffin PR 2011 Mutual information identifies sequence positions conserved within the nuclear receptor superfamily: approach reveals functionally important regions for DNA binding specificity. Nuclear Receptor Signaling 9 e001.

Willy PJ, Umesono K, Ong ES, Evans RM, Heyman RA \& Mangelsdorf DJ 1995 LXR, a nuclear receptor that defines a distinct retinoid response pathway. Genes and Development 9 1033-1045. (doi:10.1101/gad.9.9. 1033)

Wu Y, Chin WW, Wang Y \& Burris TP 2003 Ligand and coactivator identity determines the requirement of the charge clamp for coactivation of the peroxisome proliferator-activated receptor $\gamma$. Journal of Biological Chemistry 278 8637-8644. (doi:10.1074/jbc.M210910200)

Yamane K, Toumazou C, Tsukada Y-I, Erdjument-Bromage H, Tempst P, Wong J \& Zhang Y 2006 JHDM2A, a JmjC-containing H3K9 demethylase, facilitates transcription activation by androgen receptor. Cell 125 483-495. (doi:10.1016/j.cell.2006.03.027)
Zaret KS \& Carroll JS 2011 Pioneer transcription factors: establishing competence for gene expression. Genes and Development 25 2227-2241. (doi:10.1101/gad.176826.111)

Zaret KS, Watts J, Xu J, Wandzioch E, Smale ST \& Sekiya T 2008 Pioneer factors, genetic competence, and inductive signaling: programming liver and pancreas progenitors from the endoderm. Cold Spring Harbor Symposia on Quantitative Biology 73 119-126. (doi:10.1101/sqb. 2008.73.040)

Zechel C, Shen XQ, Chambon P \& Gronemeyer H 1994 Dimerization interfaces formed between the DNA binding domains determine the cooperative binding of RXR/RAR and RXR/TR heterodimers to DR5 and DR4 elements. EMBO Journal 13 1414-1424.

Zhu J, Adli M, Zou JY, Verstappen G, Coyne M, Zhang X, Durham T, Miri M, Deshpande V, De Jager PL et al. 2013 Genome-wide chromatin state transitions associated with developmental and environmental cues. Cell 152 642-654. (doi:10.1016/j.cell.2012.12.033)

Received in final form 28 November 2013

Accepted 19 December 2013

Accepted Preprint published online 20 December 2013
(C) 2014 Society for Endocrinology Printed in Great Britain
Published by Bioscientifica Ltd. 